\title{
Structural and magnetic properties of nanocrystalline $\mathrm{BaFe}_{12} \mathrm{O}_{19}$ synthesized by microwave-hydrothermal method
}

\author{
K. Sadhana $\cdot$ K. Praveena $\cdot$ S. Matteppanavar • \\ B. Angadi
}

Received: 22 November 2011 / Accepted: 21 March 2012/ Published online: 5 May 2012

(c) The Author(s) 2012. This article is published with open access at Springerlink.com

\begin{abstract}
Nanocrystalline $\mathrm{BaFe}_{12} \mathrm{O}_{19}$ powders were prepared by microwave-hydrothermal method at $200{ }^{\circ} \mathrm{C} /$ $45 \mathrm{~min}$. The as-synthesized powders were characterized by using X-ray diffraction (XRD), thermogravimetry (TG) and differential thermal analysis (DTA). The present powders were densified at different temperatures, i.e., 750, 850, 900 and $950{ }^{\circ} \mathrm{C}$ for $1 \mathrm{~h}$ using microwave sintering method. The phase formation and morphology studies were carried out using XRD and field emission scanning electron microscopy (FE-SEM). The average grain sizes of the sintered samples were found to be in the range of $185-490 \mathrm{~nm}$. The magnetic properties such as saturation magnetization and coercive field of sintered samples were calculated based on magnetization curves. A possible relation between the magnetic hysteresis curves and the microstructure of the sintered samples was investigated.
\end{abstract}

Keywords $\mathrm{BaFe}_{12} \mathrm{O}_{19} \cdot$ Microwave-hydrothermal method $\cdot$ Microwave sintering $\cdot$ Magnetic properties

\section{Introduction}

Barium ferrite with hexagonal molecular structure $\left(\mathrm{BaFe}_{12} \mathrm{O}_{19}\right)$ have been widely used in permanent magnetic

K. Sadhana $(\bowtie)$

Materials Research Center, Indian Institute of Science,

Bangalore 560 012, India

e-mail: sadhana@mrc.iisc.ernet.in

K. Praveena

School of Physics, University of Hyderabad,

Hyderabad 500 046, India

S. Matteppanavar · B. Angadi

Department of Physics, Bangalore University,

Bangalore 560 056, India materials, plastoferrite, injection-molded pieces, microwave devices, and magnetic recording media (Fujiwara et al. 1985), owing to its large magneto-crystalline anisotropy, high Curie temperature and relatively large magnetization, as well as its excellent chemical stability and corrosion resistivity. For ideal performance, barium ferrite particles are required to be of single magnetic domain, good chemical homogeneity and narrow particle size distribution. The interest in these nano-sized particles lies in our ability to affect their physical properties through manipulation of size, composition and aspect ratio to produce changes in overall physical properties.

Recent studies have shown that physical properties of nanoparticles are influenced significantly by the processing techniques (Candac et al. 1998; Pillai et al. 1995). The conventional method of producing these materials is by the solid-state reaction mixture of $\mathrm{BaCO}_{3}$ and iron oxide, and then calcining at high temperature $\left(\geq 1,200^{\circ} \mathrm{C}\right)$. The solidstate reaction method has some inherent disadvantages, such as chemical inhomogeneity, coarser particle size, and the introduction of high level of impurities during ball milling. A variety of techniques have been employed for the synthesis of nanoparticles with definite shapes and sizes (Wiley et al. 2005; Pileni et al. 1999; Murphy and Jana 2002). Hexagonal ferrites are prepared by using various synthesis routes like chemical precipitation (Pankov et al. 1993), ammonium nitrate melts (Topal et al. 2004), precipitation in alcohol (Lisjak and Drofenik 2007a, b), reverse micelle-based method (Xu et al. 2008), low-temperature combustion synthesis (Huang et al. 2004), mechanical alloying synthesis (Sharma et al. 2007), citrate precursor synthesis (Sankaranarayanan et al. 1993) and hydrothermal synthesis (Duong et al. 2007; Drofenik et al. 2007), etc. By using above synthesis methods hardagglomerated particles with large diameters and irregular 
morphologies were produced. The method of preparation strongly determines the structural and magnetic properties of hexaferrite. Therefore, in the present investigation regular morphology particles were synthesized by using microwave-hydrothermal (M-H) method (Komarneni et al. 1998). This method is versatile for preparing nanoparticles, and does not violate the laws of green chemistry. In addition, it is a low-temperature method and results in homogeneously distributed particles because of the mixing of the constituents at atomic level.

The purpose of this study is to synthesize barium hexaferrite particles with uniformly mixed atomic arrangements. It was hypothesized that the calcination temperature required for the crystallization of these barium hexaferrite nanoparticles would be lower than the temperature required for the formation of bulk phases. The effects of calcination temperature on particle size, morphology, crystallinity and magnetic properties were systematically examined.

\section{Experimental method}

The nanocrystalline $\mathrm{BaFe}_{12} \mathrm{O}_{19}$ powders have been synthesized by using microwave-hydrothermal (M-H) method. The high purity $(99.9 \%)$ chemicals of barium nitrate $\left[\mathrm{Ba}\left(\mathrm{NO}_{3}\right)_{2} \cdot 6 \mathrm{H}_{2} \mathrm{O}\right]$ and ferric nitrate $\left[\mathrm{Fe}\left(\mathrm{NO}_{3}\right)_{2} \cdot 9 \mathrm{H}_{2} \mathrm{O}\right]$ were weighted and the molar ratio of powders was adjusted to $\mathrm{Ba}: \mathrm{Fe}=1: 12$ to obtain the composition $\mathrm{BaFe}_{12} \mathrm{O}_{19}$. The powders were dissolved in de-ionized water and $\mathrm{NaOH}$ was added with controlling of $\mathrm{pH} \sim 12$. The brown precipitation was heated to $80{ }^{\circ} \mathrm{C} / 30$ min with constant stirring to obtain the homogeneous mixture. The mixture was then treated in a Teflon-lined vessel using a microwave digestion system (Model Discover, CEM Corp.). The system is controlled by pressure and can attain maximum pressure of $200 \mathrm{psi}$, which is equivalent to $194{ }^{\circ} \mathrm{C}$, based on steam tables. In the present investigation all the samples were synthesized at $200{ }^{\circ} \mathrm{C} / 45 \mathrm{~min}$. The reaction vessel is connected to a pressure transducer that monitors and controls the pressure during synthesis. The time, pressure and power were computer controlled. The products obtained were filtered, and then washed repeatedly with de-ionized water, followed by freeze-drying overnight. The prepared powders were weighted and the percentage yields were calculated from the expected total amount based on the solution concentration and volume and the amount that was actually crystallized. An average $94 \%$ yield was obtained.

The as-synthesized powders were characterized by using Phillips PAN analytical X'pert powder X-ray diffraction (XRD) with $\mathrm{Cu}-\mathrm{K}_{\alpha}$ radiation $(\lambda=1.5406 \AA)$. The obtained powders were mixed with an appropriate amount of $2 \mathrm{wt} \%$ polyvinyl alcohol as a binder. Then the powder was uniaxially pressed at a pressure of $500 \mathrm{~kg} / \mathrm{cm}^{2}$ to form green pellet specimens. The compacts were annealed at different temperature $750,850,900$ and $950{ }^{\circ} \mathrm{C}$ for $1 \mathrm{~h}$ using microwave sintering method (Murthy 2002). The theoretical density $\left(d_{\mathrm{x}}\right)$, bulk density $\left(d_{\mathrm{b}}\right)$, and porosity $(\mathrm{P})$ were determined from the following formulaes,

$d_{\mathrm{x}}=\frac{2 M}{\mathrm{NV}} ; \quad d_{\mathrm{b}}=\frac{W_{\mathrm{air}}}{W_{\text {air }}-W_{\text {water }}} ; \quad P=1-\frac{d_{\mathrm{b}}}{d_{\mathrm{x}}}$

where $M$ is molecular weight of the sample, $N$ is Avogadro number, $W_{\text {air }}$ is weight of the sample in air and $W_{\text {water }}$ is weight of the sample in water. The phase and morphology of the sintered samples were studied by using XRD and field emission scanning electron microscopy (FE-SEM). The room temperature saturation magnetization $\left(M_{\mathrm{s}}\right)$ and coercive field $\left(H_{\mathrm{c}}\right)$ were studied using vibrating sample magnetometer (VSM) (Lakeshore, USA) up to $15 \mathrm{kOe}$.

\section{Results and discussion}

Figure 1 shows the room temperature XRD pattern of $\mathrm{BaFe}_{12} \mathrm{O}_{19}$ prepared by $\mathrm{M}-\mathrm{H}$ method. The peaks between $2 \theta=32^{\circ}-38^{\circ}$ is not showing well resolved peaks, suggesting the small crystallite size as well as low degree of the crystallinity of the sample. The observed peaks all correspond to the barium hexaferrite structure. The intensities differ from the standard diffraction pattern (JCPDS no: 84-0757) due to the presence of very small particles with a very high aspect ratio. The synthesized particles grow extensively in the $a b$-plane, while a very limited growth was observed in the c-direction. Consequently, only a few unit cells grew in the $c$-direction and the peaks of the respective planes show unusually low intensity (Drofenik et al. 2011).The intermediate phases like $\mathrm{Fe}_{2} \mathrm{O}_{3}$ and $\mathrm{BaFe}_{2} \mathrm{O}_{4}$ were observed and the diffraction planes are matched well with JCPDS card nos 89-2810 and 77-2337.

Figure 2 shows the TG/DTA curves for as-synthesized barium hexaferrite powders prepared by microwavehydrothermal method. The weight loss corresponding to peaks in DTA are not significant. The curve can be divided into four steps; the first peak at $290{ }^{\circ} \mathrm{C}$ is due to removal of any absorbed/adsorbed moisture from the sample surface and evaporation of residual nitrate. The second peak at $430{ }^{\circ} \mathrm{C}$ represents the decomposition of the hydroxides of barium and iron into their corresponding metal oxides and the third exothermic peak around $580{ }^{\circ} \mathrm{C}$ corresponds to the formation of hexagonal phase with small amounts of $\mathrm{BaFe}_{2} \mathrm{O}_{4}$. The reaction of formation takes place in the range of $650-950{ }^{\circ} \mathrm{C}$. A. Ataie et al., have reported 634 and $733{ }^{\circ} \mathrm{C}$ as the lowest temperature for the formation of barium hexaferrites and strontium hexaferrites using co-precipitation and modified co-precipitation methods, 


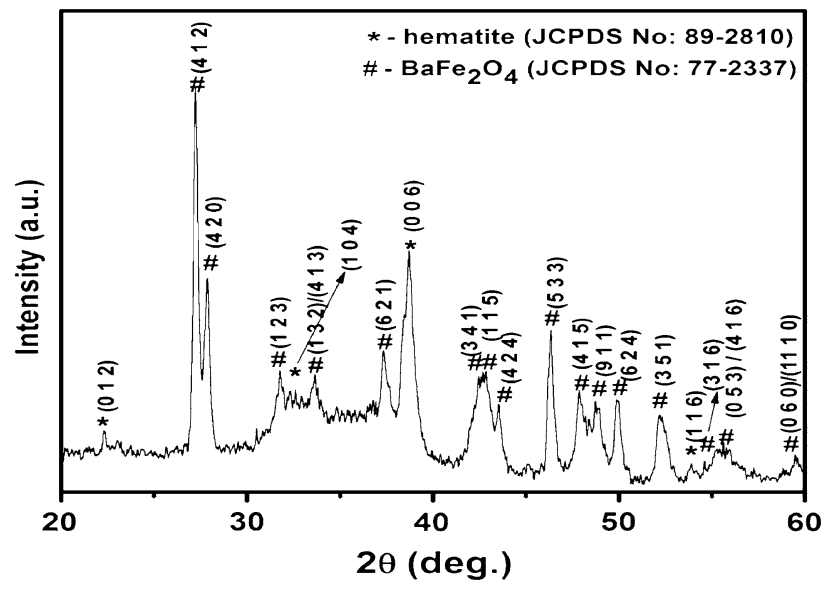

Fig. 1 XRD pattern of microwave-hydrothermally synthesized $\mathrm{BaFe}_{12} \mathrm{O}_{19}$ powder

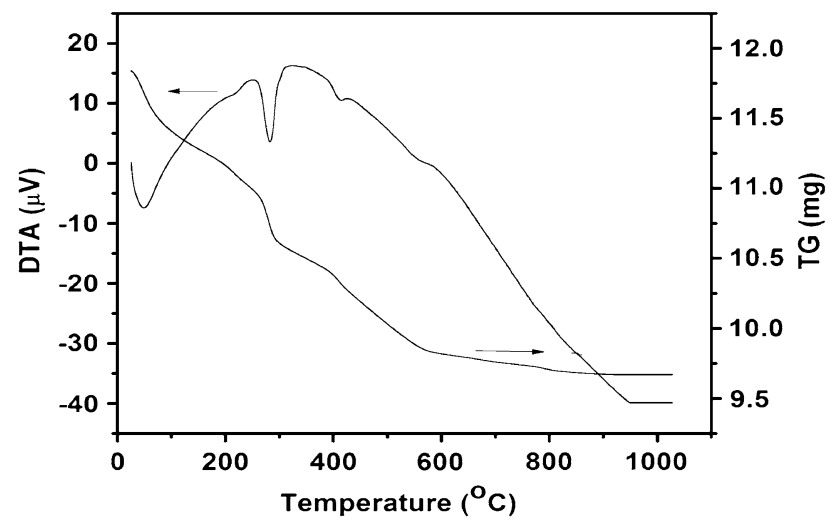

Fig. 2 Thermal analysis studies of as prepared $\mathrm{BaFe}_{12} \mathrm{O}_{19}$ powders

respectively (Huang et al. 2003; Mali and Ataie 2004; Bahadur et al. 2006; Yu and Liu 2006; Ataie and Manesh 2001). There is no noticeable weight loss observed up to $1,000{ }^{\circ} \mathrm{C}$.

Figure 3 shows the XRD patterns of microwave-sintered barium hexaferrite samples. It can be seen from the figures that the sample sintered at 750,850 and $900{ }^{\circ} \mathrm{C}$ contains small amount of $\alpha-\mathrm{Fe}_{2} \mathrm{O}_{3}$ and $\mathrm{BaFe}_{2} \mathrm{O}_{4}$ phase along with barium hexaferrite peaks. As the sintering temperature increases, the reaction between the barium ions and $\alpha-\mathrm{Fe}_{2} \mathrm{O}_{3}$ phase is able to form interstitial solid solution to form hexagonal phase. The single barium ferrite phase without any intermediate phase was observed at $950{ }^{\circ} \mathrm{C}$ is due to the interstitial diffusion of barium atoms into the cation vacancy of $\mathrm{Fe}_{2} \mathrm{O}_{3}$. The amount of barium hexaferrite increases monotonically with the increase in temperature and appears as a major phase at $950{ }^{\circ} \mathrm{C}$. No structural change is observed at $1,000{ }^{\circ} \mathrm{C}$ (not given in XRD).

According to Chen and Chen, barium ferrite nanoparticles synthesized by the co-precipitation method formed the hexagonal phase after calcination at $700{ }^{\circ} \mathrm{C} / 2 \mathrm{~h}$

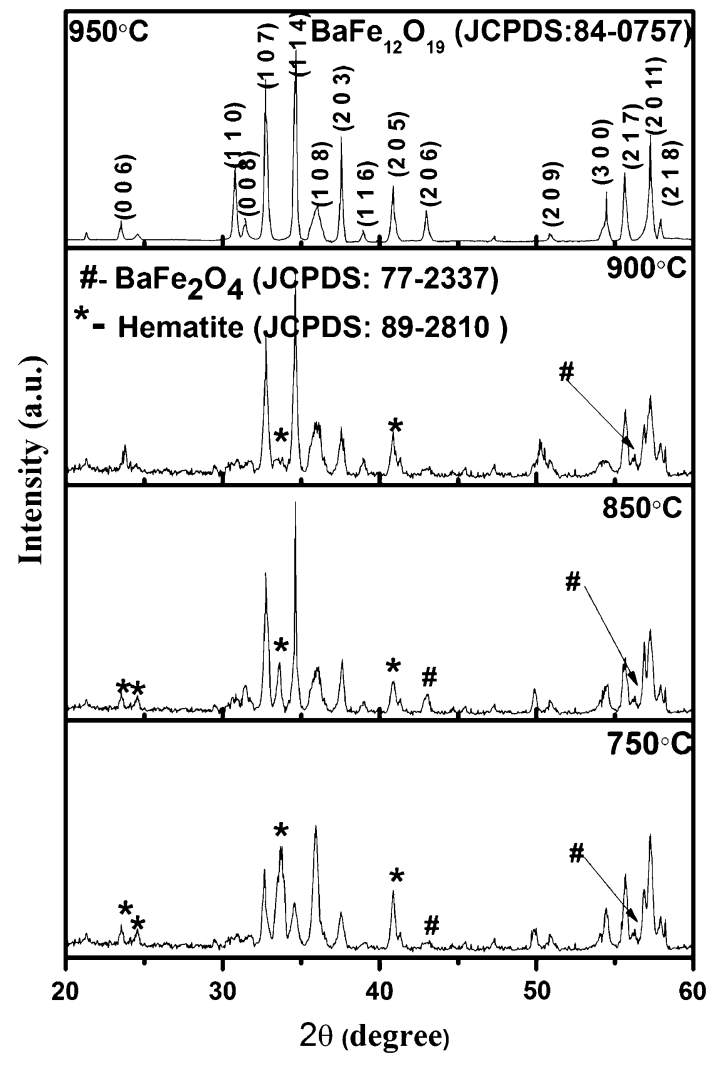

Fig. 3 XRD patterns of microwave-sintered $\mathrm{BaFe}_{12} \mathrm{O}_{19}$ samples

(Dong-Hwang Chen and Yuh-Yuh Chen 2001). Yu and Liu (2006) reported that hexagonal-phase barium ferrite particles resulted after calcination above $650{ }^{\circ} \mathrm{C} / 5 \mathrm{~h}$. Their single-hexagonal ferrite phase was observed at $700{ }^{\circ} \mathrm{C}$. In the last two methods, the resulting amorphous barium ferrite was a gel rather than a particle. But, in the present investigation a single-phase barium hexaferrite was observed at $950{ }^{\circ} \mathrm{C}$.

It is clear from the Table 1 that the value of lattice constant was increasing with an increase of sintering temperature due to the lattice growth. With increasing heat treatment temperatures from 750 to $950{ }^{\circ} \mathrm{C}$ the relative intensity of the peaks increases indicating an increase in particle size. The bulk density of the sintered samples was

Table 1 Data of lattice constants, density and porosity of $\mathrm{BaFe}_{12} \mathrm{O}_{19}$

\begin{tabular}{llllll}
\hline $\begin{array}{l}\text { Sintering } \\
\text { temperature } \\
\left({ }^{\circ} \mathrm{C} / 1 \mathrm{~h}\right)\end{array}$ & $\begin{array}{l}\text { Lattice } \\
\text { parameters }\end{array}$ & \begin{tabular}{l} 
Theoretical \\
\cline { 2 - 3 } density $\left(d_{\mathrm{x}}\right)$ \\
$\left(\mathrm{g} / \mathrm{cm}^{3}\right)$
\end{tabular} & $\begin{array}{l}\text { Bulk } \\
\text { density }\left(d_{\mathrm{b}}\right)\end{array}$ & $\begin{array}{l}\text { Porosity } \\
\left(\mathrm{g} / \mathrm{cm}^{3}\right)\end{array}$ \\
\hline 750 & 5.888 & 22.885 & 5.371 & 4.587 & 14 \\
850 & 5.890 & 23.112 & 5.314 & 4.659 & 12 \\
900 & 5.891 & 23.155 & 5.303 & 4.734 & 10 \\
950 & 5.893 & 23.174 & 5.295 & 4.812 & 9 \\
\hline
\end{tabular}


calculated using Archimedes principle and it was found to be increasing and porosity of the present samples are in the range of $9-14 \%$ that of the theoretical density.

Figure $4 \mathrm{a}-\mathrm{d}$ shows the FE-SEM pictures of microwavesintered barium hexaferrite at different sintering temperatures. The morphology of the grains is found to be in hexagonal shape (plate like). This type of shape was observed for hydrothermal process (Lin et al. 1990; Liu et al. 1999; $\mathrm{Zi}$ et al. 2008). For the samples sintered at 750 and $8500^{\circ} \mathrm{C}$, over the plate-shaped grains some spherical grains are observed which are attributed to the intermediate nonmagnetic phases of barium hexaferrites which can be clearly observed in XRD patterns (Fig. 3). The value of grain sizes at different sintering temperature is given in Table 2. It shows that as the sintering temperature increases from 750 to $950{ }^{\circ} \mathrm{C}$, the grain size also increases due to the grain growth kinematics. The isotropic characteristic in the shape of the product particles is due to the rapid homogenous nucleation accelerated by microwaves which limits the secondary crystal growth. Compared with the conventional sintering, microwave sintering induces short calcination time and low calcination temperature. The heating rates during the calcination process are high which
Table 2 Experimental data of magnetic properties

\begin{tabular}{lllllr}
\hline $\begin{array}{l}\text { Sintering temperature } \\
\left({ }^{\circ} \mathrm{C} / 1 \mathrm{~h}\right)\end{array}$ & $\begin{array}{l}\text { Grain size } \\
(\mathrm{nm})\end{array}$ & $\begin{array}{l}M_{\mathrm{s}} \\
(\mathrm{emu} / \mathrm{g})\end{array}$ & $\begin{array}{l}M_{\mathrm{r}} \\
(\mathrm{emu} / \mathrm{g})\end{array}$ & $\begin{array}{l}M_{\mathrm{r}} / \\
M_{\mathrm{s}}\end{array}$ & $\begin{array}{l}H_{\mathrm{c}} \\
(\mathrm{Oe})\end{array}$ \\
\hline 750 & 185 & 33 & 17 & 0.51 & 805 \\
850 & 320 & 36 & 18 & 0.50 & 886 \\
900 & 417 & 43 & 22 & 0.51 & 1,336 \\
950 & 490 & 47 & 20 & 0.43 & 1,050 \\
\hline
\end{tabular}

is much higher than the conventional heating rate. In addition, heat is generated internally within the material, instead of originating from external sources for microwave calcination, and the specimen set rotates continuously, so uniform heating is induced. Compared to conventionally sintered samples, microwave-sintered samples are homogeneously crystallized and has great advantages on synthetic efficiency and energy consumption. The larger grain indicates the smaller results in a decrease of grain boundary and surface energy. The larger is the crystallite size, the more energetically stable. But the grain growth is very small due to the low sintering time. The plate-like shape of the grains clearly indicates the formation of barium
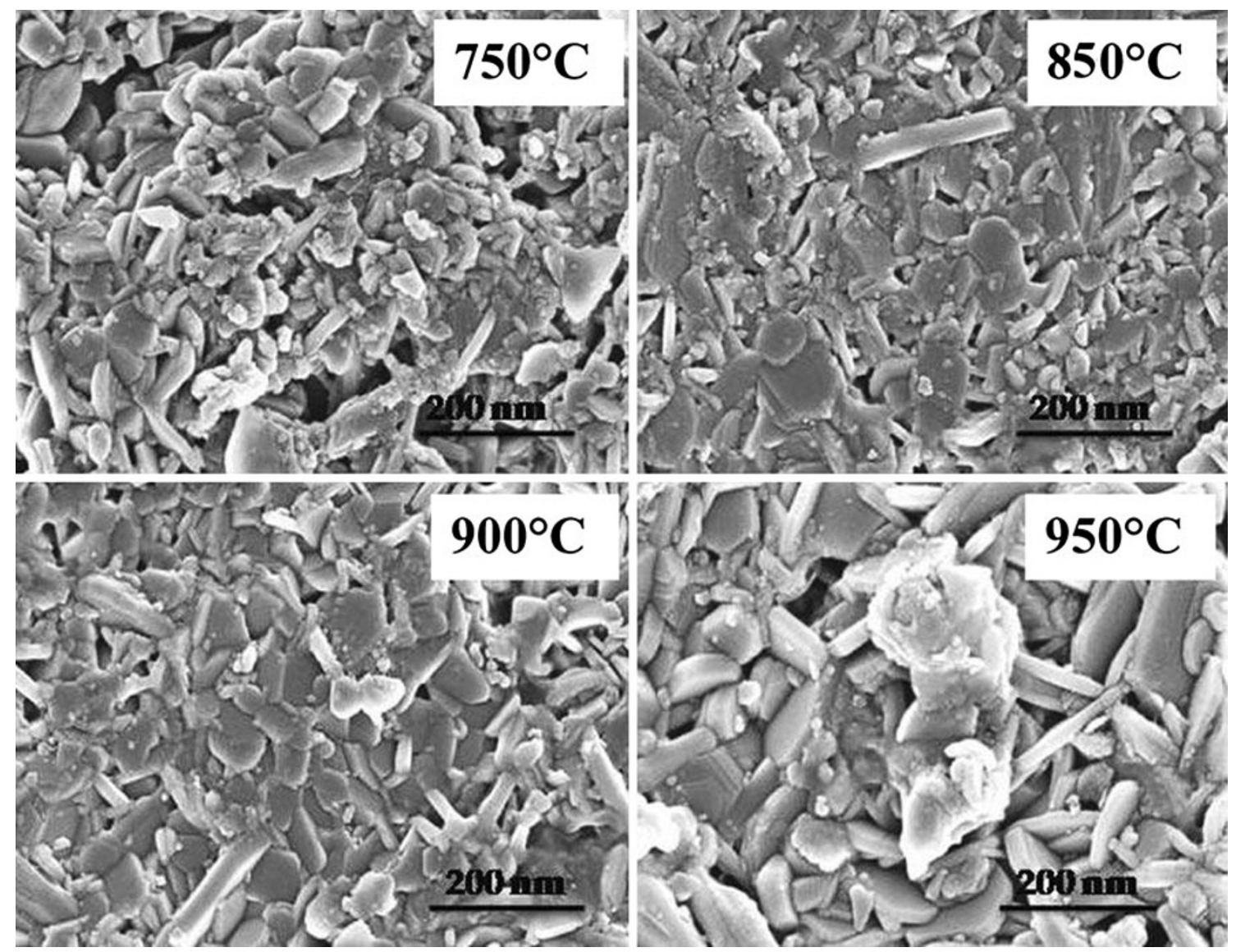

Fig. 4 FE-SEM images of microwave-sintered $\mathrm{BaFe}_{12} \mathrm{O}_{19}$ samples<smiles>[CH]1CC1</smiles>

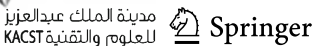


hexaferrites at $950{ }^{\circ} \mathrm{C}$, which is confirmed from the XRD. According to literature (Sharma et al. 2008, 2009), barium and strontium hexaferrite nanoparticles with hexagonal pyramidal and hexagonal plate-like morphology are best for the electromagnetic wave absorption applications, effective radar absorbing materials (RAM). The average grain sizes of the sintered samples were found to be in the range of $185-490 \mathrm{~nm}$.

Figure 5 shows the M-H loops of microwave-sintered barium hexaferrites at room temperature. The data of magnetic properties such as saturation magnetization $\left(M_{\mathrm{s}}\right)$, remanence magnetization $\left(M_{\mathrm{r}}\right)$ and coercive field $\left(H_{\mathrm{c}}\right)$ are given in Table 2. It can be seen from the table that as the sintering temperature increases the values of $M_{\mathrm{s}}, M_{\mathrm{r}}$ and grain size increases. The increase in $M_{\mathrm{s}}$ with sintering temperature indicates that the proportion of $\mathrm{BaFe}_{12} \mathrm{O}_{19}$ phase is increased. The values of $M_{\mathrm{s}}$ are found to be low as compared with the bulk ferrite (Shirk and Buessem 1969). The reduction in $M_{\mathrm{s}}$ might be due to the presence of small amount of $\mathrm{Fe}_{2} \mathrm{O}_{3}$ phase. The squareness ratio $\left(M_{\mathrm{r}} / M_{\mathrm{s}}\right)$ is found to be around 0.5 which is the expected value for randomly packed domains ( $\mathrm{Li} 1986)$.

The value of coercive field increased from 750 to $900{ }^{\circ} \mathrm{C}$ and then decreased with further increase of temperature up to $950{ }^{\circ} \mathrm{C}$. The change in coercive field is related to increase of the grain size due to sintering, the change in microstructure and the presence of residual of $\mathrm{Fe}_{2} \mathrm{O}_{3}$. In addition, the barium hexaferrite powder exhibited particle coarsening (plate-like hexagonal structure) and grain growth at such a high annealing temperature. The powders that annealed at $950{ }^{\circ} \mathrm{C}$ have very long branched hexagonal structure with pores between the crystals leading to a lower coercive field.

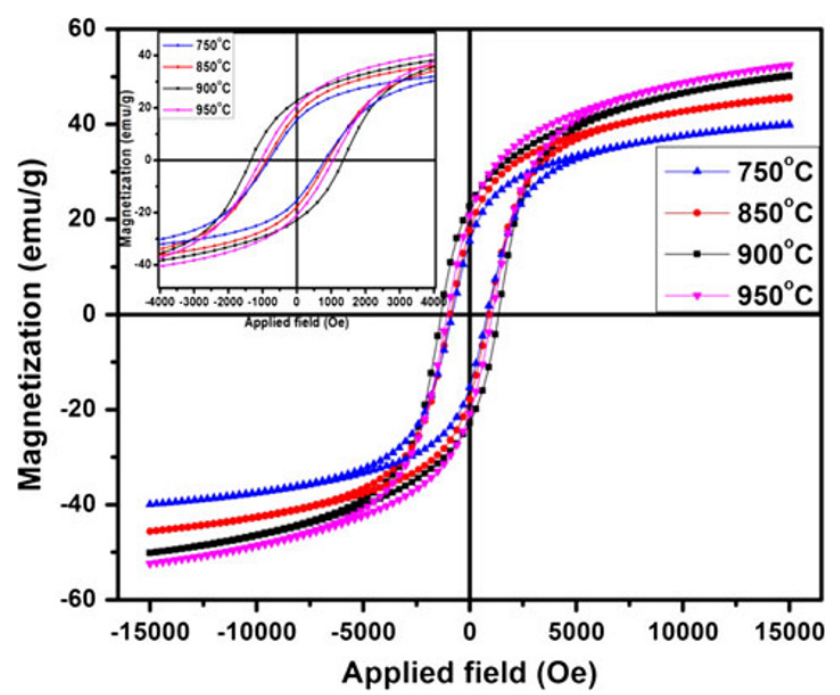

Fig. 5 Magnetic hysteresis loops of hexaferrite at different annealing temperatures

\section{Conclusions}

The nanocrystalline barium hexaferrite powders were synthesized by microwave-hydrothermal method. The annealed powders exhibited a grain size ranging from 185 to $490 \mathrm{~nm}$. The plate-shaped grains clearly show the formation of hexaferrite at $9500^{\circ} \mathrm{C}$, the results are consistent with the TG/DTA curves. The $M_{\mathrm{s}}$ of $43 \mathrm{emu} / \mathrm{g}$ and $H_{\mathrm{c}}$ of 1336 Oe was obtained for the samples annealed at $900{ }^{\circ} \mathrm{C} / 1 \mathrm{~h}$

Acknowledgments The authors are thankful to Council of Scientific and Industrial Research (CSIR), New Delhi, India, for providing Research Associate fellowship to carry out the present work. The author (K.S.) is thankful to Prof. S.R. Murthy, Osmania University, for providing microwave-hydrothermal equipment to carryout synthesis work and to Dr. S. Srinath, School of Physics, University of Hyderabad, for providing FE-SEM facilities. The author, K.S. is grateful to Prof. K.B.R. Varma, Chairman, Materials Research Center (MRC), Indian Institute of Science (IISc), Bangalore, India, for fruitful discussions.

Open Access This article is distributed under the terms of the Creative Commons Attribution License which permits any use, distribution, and reproduction in any medium, provided the original author(s) and the source are credited.

\section{References}

Ataie A, Manesh SH (2001) Synthesis of ultra-fine particles of strontium hexaferrite by a modified co-precipitation method. J Eur Ceram Soc 21:1951-1955

Bahadur D, Rajakumar S, Kumar A (2006) Influence of fuel ratios on auto combustion synthesis of barium ferrite nano particles. J Chem Sci 118:15-21

Candac TS, Carpenter EE, O'Connor CJ, John VT, Li S (1998) Magnetic properties of a series of ferrite nanoparticles synthesized in reverse micelles. IEEE Trans Magn 34:1111-1113

Dong-Hwang C, Yuh-Yuh C (2001) Synthesis of barium ferrite ultrafine particles by coprecipitation in the presence of polyacrylic acid. J Coll Inter Sci 235:9-14

Drofenik M, Kristl M, Žnidaršič A, Hanžel D, Lisjak D (2007) Hydrothermal synthesis of Ba- hexaferrite nanoparticles. J Am Ceram Soc 90:2057-2061

Drofenik M, Ban I, Makovec D, Žnidaršič A, Jagličić Z, Lisjak D, Hanžel D (2011) The hydrothermal synthesis of super-paramagnetic barium hexaferrite particles. Mater Chem Phys 127:415-419

Duong GV, Turtelli RS, Thuan BD, Linh DV, Hanh N, Groessinger R (2007) Magnetic properties of nanocrystalline $\mathrm{BaFe}_{12} \mathrm{O}_{19}$ prepared by hydrothermal method. J Non Cryst Solids 353:811-813

Fujiwara T, Isshiki M, Suzuki T, Ito T, Ido T (1985) Relations between coercivity and recording performances for Ba-ferrite particulate perpendicular media. IEEE Trans Magn 21:1486-1488

Huang JG, Zhuang HR, Li WL (2003) Synthesis and characterization of nano crystalline $\mathrm{BaFe}_{12} \mathrm{O}_{19}$ powders by low temperature combustion. Mater Res Bull 38:149-159

Huang J, Zhuang H, Li WL (2004) Synthesis and characterization of nano-crystalline $\mathrm{BaFe}_{12} \mathrm{O}_{19}$. Mater Res Bull 38:149-159

Komarneni S, D’Arrigo MC, Leonelli C, Pellacani GC, Katsuki H (1998) Microwave-hydrothermal synthesis of nanophase ferrites. J Am Ceram Soc 81(11):3041-3043 
Li S (1986) Grain size effects on magnetic properties and core process of recording head ferrites. IEEE Trans Magn 22:14-18

Lin CH, Shin ZW, Chin TS, Wang ML, Yu YC (1990) Hydrothermal processings to produce magnetic particulates. IEEE Trans Magn 26:15-17

Lisjak D, Drofenik M (2007a) The mechanisms of low-temperature formation of barium hexaferrites. J Eur Ceram Soc 27:45154520

Lisjak D, Drofenik M (2007b) The influence of the Co-precipitation conditions on the low-temperature formation of barium hexaferrite. J Mater Sci 42:8606-8612

Liu X, Wang J, Gan LM, Ng SC (1999) Improving the magnetic properties of hydrothermally synthesized barium ferrite. J Magn Magn Mater 195:452-459

Mali A, Ataie A (2004) Influence of the metal nitrates to citric acid molar ratio on the combustion process and phase constitution of barium hexaferrite particles prepared by sol-gel combustion method. Ceram Int 30:1979-1983

Murphy CJ, Jana NR (2002) Controlling the aspect ratio of inorganic nanorods and nanowires. Adv Mater 14:80-82

Murthy SR (2002) Low temperature sintering of NiCuZn ferrite and its electrical, magnetic and elastic properties. J Mat Sci Lett 21:657-660

Pankov VV, Pernet M, Germi P, Mollard P (1993) Fine hexaferrite particles for perpendicular recording prepared by the coprecipitation method in the presence of an inert component. J Magn Magn Mater 120:69-72

Pileni MP, Ninham BW, Kryzwicki TG, Lisiecki JT, Filankembo A (1999) Direct relationship between shape and size of template synthesis of copper metal particles. Adv Mater 11:1358-1362

Pillai V, Kumar P, Hou MJ, Ayyub P, Shah DO (1995) Preparation of nanoparticles of silver halides, superconductors and magnetic materials using water-in-oil microemulsions as nano-reactors. Adv Coll Int Sci 55:241-269
Sankaranarayanan VK, Pankhurst QA, Dickson DPE, Johnson CE (1993) An investigation of particle size effects on Ultrafine barium ferrite. J Magn Magn Mater 125:199-208

Sharma P, Rocha RA, de Medeiros SN, Paesano A (2007) Structural and magnetic studies on barium hexaferrites prepared by mechanical alloying and conventional route. J Alloys Compd 443:37-43

Sharma R, Agarwala RC, Agarwala V (2008) Development of radar absorbing nano crystals under thermal irradiation. J Nano Res 2:91-104

Sharma R, Agarwala RC, Agarwala VA (2009) Comparative study on process-properties correlation of nano radar absorbing heat treated materials. Adv Mater Res 67:39-44

Shirk BT, Buessem WR (1969) Temperature dependence of $\mathrm{M}_{\mathrm{s}}$ and $\mathrm{K}_{1}$ of $\mathrm{BaFe}_{12} \mathrm{O}_{19}$ and $\mathrm{SrFe}_{12} \mathrm{O}_{19}$ single crystals. J Appl Phys 40:1294-1296

Topal U, Ozkan H, Sozery H (2004) Synthesis and characterization of nanocrystalline $\mathrm{BaFe}_{12} \mathrm{O}_{19}$ obtained at $850{ }^{\circ} \mathrm{C}$ by using ammonium salts. J Magn Magn Mater 284:416-422

Wiley B, Sun Y, Chen J, Cang Hu, Li ZY, Li X, Xia Y (2005) Shapecontrolled synthesis of silver and gold nanostructures. Mater Res Bull 30:356-361

Xu P, Han X, Zhao H, Liang Z, Wan J (2008) Effect of stoichiometry on the phase formation and magnetic properties of $\mathrm{BaFe}_{12} \mathrm{O}_{19}$ nanoparticles by reverse micelle technique. Mater Lett 62:1305-1308

Yu HF, Liu PC (2006) Effects of $\mathrm{pH}$ and calcination temperatures on the formation of citrate-derived hexagonal barium ferrite particles. J Alloys Comp 416:222-227

Zi ZF, Sun YP, Zhu XB, Yang ZR, Dai ZM, Song WH (2008) Structural and magnetic properties of $\mathrm{SrFe}_{12} \mathrm{O}_{19}$ hexaferrite synthesized by a modified chemical Co-precipitation method. J Magn Magn Mater 320:2746-2751 